\title{
Improved Oxygen Reduction Activity of Transition Metal-Chelating Ordered Mesoporous Carbon Fuel Cell Catalysts by Milder Template Removal
}

\author{
C. Janson ${ }^{1}$ - A. E. C. Palmqvist ${ }^{1}$
}

Received: 26 October 2018 / Accepted: 31 January 2019 / Published online: 15 February 2019

(c) The Author(s) 2019

\begin{abstract}
In the synthesis of iron-chelating ordered mesoporous nitrogen-functionalized carbon ( $\mathrm{Fe}-\mathrm{OMC}$ ) catalysts, the removal of the silica template is a crucial and critical step. The silica removal method used today for the $\mathrm{Fe}-\mathrm{OMCs}$ is based on the very toxic hydrofluoric acid (HF), which usage should be limited where possible. Therefore, the aim of this study is to establish a mild (user-friendly), yet efficient, etch method based on dilute sodium hydroxide $(\mathrm{NaOH})$, which does not impair the catalytic performance of the catalyst, to replace the currently used HF method. A comparison between catalysts etched with HF versus $\mathrm{NaOH}$ was performed in order to gain understanding how the two etch methods influence the final catalysts in terms of electrochemical, structural and catalytic properties. The $\mathrm{NaOH}$ etch was found to successfully remove the silica template, and interestingly, also improve the catalytic performance. The improved activity is explained by a carbon activation process occurring in the catalyst treated with the $\mathrm{NaOH}$ etch. With these findings, we show that it is possible to remove the silica in a more user-friendly way and simultaneously increase the catalysts' performance by activation of the carbon.
\end{abstract}

\section{Graphical Abstract}

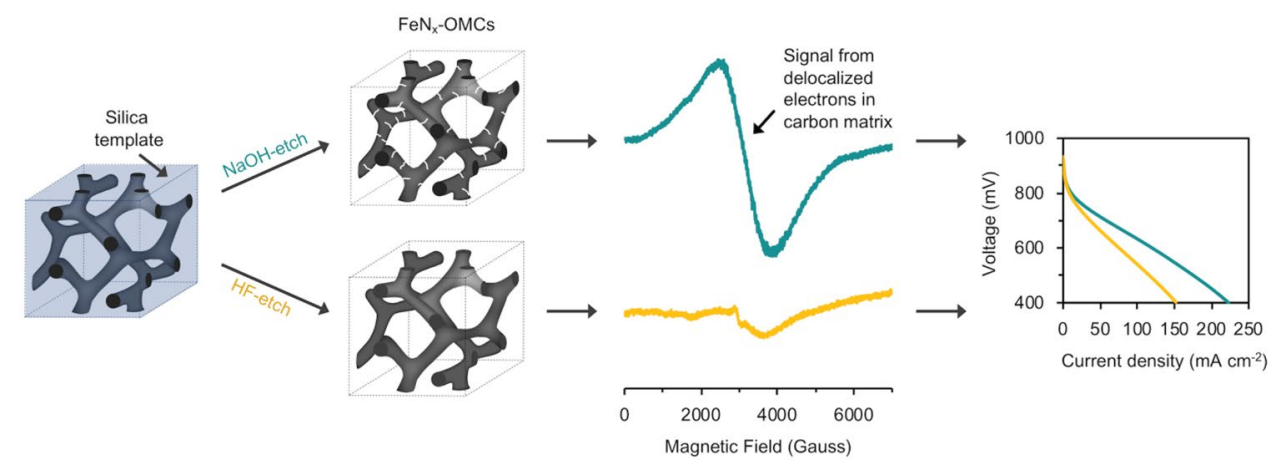

Keywords Electrocatalyst $\cdot$ Cathode $\cdot$ PEM fuel cell $\cdot$ Silica template removal $\cdot$ Electron paramagnetic resonance

\section{Introduction}

Polymer electrolyte membrane fuel cells (PEMFCs) are interesting devices since they efficiently convert chemi-

A. E. C. Palmqvist

anders.palmqvist@chalmers.se

1 Department of Chemistry and Chemical Engineering, Chalmers University of Technology, 41296 Gothenburg, Sweden cal energy directly into electrical energy. A drawback with PEMFCs is the high price mainly caused by use of expensive platinum catalysts. With the aim to make PEMFCs cost competitive, interesting noble metal-free catalysts have been developed in recent years [1-6]. One such catalyst is the 
iron-chelating ordered mesoporous nitrogen-functionalized carbon (Fe-OMC) catalysts [7-9]. These catalysts are prepared via a hard template method in which an ordered mesoporous silica acts as a template for the formation of a carbon/silica composite. By selective removal of the silica from the composite the method provides a carbon-based catalyst with high specific surface area and large pore volume and offers tunable pore diameters and surface properties of the carbon matrix. The high specific surface area and pore volume are beneficial in catalysts since the number of catalytically active sites can be increased per unit mass and volume of the catalyst, providing high power densities in the fuel cell. The selective removal of the silica template can in principle be achieved either by etching in acidic hydrofluoric acid (HF) or using alkaline potassium or sodium hydroxide $(\mathrm{KOH}$ or $\mathrm{NaOH})$ solutions. In all work reported on the Fe-OMCs for fuel cells so far, the catalysts have been prepared using an HF etch to remove the silica. The use of HF has been found to leave the chelating properties of the nitrogen-functionalized carbon and transition metal ions intact and the material electrocatalytically active after the etch [7-9].

However, HF is a very harmful, toxic and corrosive acid, and its use should be minimized where possible. A better option and less toxic alternative would therefore be to use an alkaline solution such as $\mathrm{NaOH}$ or $\mathrm{KOH}$. $\mathrm{NaOH}$ as an etchant for silica, to produce mesoporous carbons for electrode/catalyst applications, can be found in numerous studies [10-13]. Surprisingly, very few studies reflect on the different effects the two etch methods ( $\mathrm{NaOH}$ and $\mathrm{HF}$ ) have on the carbon and its catalytic properties [14]. The $\mathrm{NaOH}$ etch method may in fact lead to other advantageous properties of the catalysts since $\mathrm{NaOH}$ is known to activate carbons at high temperatures and to produce highly porous carbons with high specific surface area and specific surface properties $[15,16]$. Consequently, $\mathrm{NaOH}$ has potential to contribute to two effects in the same synthesis. First as etchant for the silica template removal to obtained mesoporous carbons and secondly in the activation of the carbons to achieve higher specific surface area and improved catalytic activity.

The main purpose of this study is to establish an efficient and mild (user-friendly) $\mathrm{NaOH}$ etch method, to replace the currently used HF method in the synthesis of $\mathrm{Fe}-\mathrm{OMC}$ catalysts. Furthermore, we want to verify if the $\mathrm{NaOH}$, used for the silica etch, simultaneously can be used to activate the carbon and provide catalysts with improved catalytic properties. The samples used in this study, were also used in another study [17] investigating how the choice of carbon precursor influenced the formation of $\mathrm{Fe}-\mathrm{N}_{\mathrm{x}}$ chelates and the carbon matrix structure and its properties. From that study we chose the two best performing samples to investigate the influence of the etch method on the properties of the formed $\mathrm{Fe}-\mathrm{OMC}$ catalysts.

\section{Experimental Section}

Mesoporous silica (KIT-6) was prepared and used as a template for synthesis of mesoporous carbon catalysts. Four catalysts were prepared combining furfurylamine ( $\geq 99 \%$ Sigma-Aldrich), furfuryl alcohol (98\% Sigma-Aldrich), and anhydrous iron chloride (98\% Sigma-Aldrich) [17]. The precursors were mixed together in the order shown in Table 1 . Typically, a mixture of reactants 1 and 2 was well mixed for 15 min followed by the addition and mixing of reactant 3 . The iron to furfurylamine/furfuryl alcohol molar ratio was about 1:180. After mixing, most of the iron chloride was dissolved but some small pieces of undissolved salt remained. The liquid part of the mixture, was subsequently impregnated in the silica template and soaked overnight, followed by a heat treatment in air at $100{ }^{\circ} \mathrm{C}$ for $2 \mathrm{~h}$. A second impregnation was made and followed by a heat treatment in air at $160{ }^{\circ} \mathrm{C}$ for $2 \mathrm{~h}$. The sample was then pyrolyzed in an inert atmosphere at $950{ }^{\circ} \mathrm{C}$ for $2 \mathrm{~h}$. Thereafter, each sample was divided into two parts for the two different methods of silica removal. For samples AmFe-HF and AmFeAl-HF, the silica template was removed by etching with $40 \% \mathrm{HF}$ for $20 \mathrm{~h}$ at room temperature followed by rinsing with water. For samples AmFe- $\mathrm{NaOH}$ and $\mathrm{AmFeAl}-\mathrm{NaOH}$, the silica template was removed using $1 \mathrm{M} \mathrm{NaOH}\left(50 \mathrm{vol} \% \mathrm{H}_{2} \mathrm{O} / 50 \mathrm{vol} \%\right.$ ethanol) for $3^{*} 20 \mathrm{~h}$ at $80^{\circ} \mathrm{C}$ followed by rinsing with water. Finally, for all four samples, an additional acid treatment was carried out with $0.5 \mathrm{M} \mathrm{H}_{2} \mathrm{SO}_{4}$ (95-98\% Sigma-Aldrich) for $6 \mathrm{~h}$ at $80{ }^{\circ} \mathrm{C}$ followed by another pyrolysis treatment in inert atmosphere at $950{ }^{\circ} \mathrm{C}$ for $2 \mathrm{~h}$. Electrochemical evaluation of the prepared catalyst materials was done by single cell fuel cell measurements using a commercial PEMFC from Scribner Associates Inc. A commercial Pt/C catalyst $(10 \mathrm{wt} \% \mathrm{Pt}$ with $0.5 \mathrm{mg} \mathrm{Pt} / \mathrm{cm}^{2}$ from FuelCell Inc.) was used at the anode side, while the discussed catalyst materials were used
Table 1 Name of the catalysts, mixing order of the reactants and silica etch method

\begin{tabular}{lllll}
\hline Catalyst & Reactant 1 & Reactant 2 & Reactant 3 & Etch method \\
\hline AmFe-HF & Furfurylamine & $\mathrm{FeCl}_{3}$ & & $\mathrm{HF}$ \\
AmFe-NaOH & Furfurylamine & $\mathrm{FeCl}_{3}$ & & $\mathrm{NaOH}$ \\
$\mathrm{AmFeAl}-\mathrm{HF}$ & Furfurylamine & $\mathrm{FeCl}_{3}$ & Furfuryl alcohol & $\mathrm{HF}$ \\
$\mathrm{AmFeAl}-\mathrm{NaOH}$ & Furfurylamine & $\mathrm{FeCl}_{3}$ & Furfuryl alcohol & $\mathrm{NaOH}$ \\
\hline
\end{tabular}


as cathode catalysts with a loading of $5-6 \mathrm{mg} \mathrm{Fe}-\mathrm{OMC} /$ $\mathrm{cm}^{2}$. The electrode area used was $2.56 \mathrm{~cm}^{2}$. A commercial ionomer (Nafion ® 115 membrane from Sigma) completed the MEA. Detailed parameters for the MEA preparation are given in [18]. All measurements discussed here were done at $80{ }^{\circ} \mathrm{C}$. The cell was fueled by fully humidified $100 \%$ $\mathrm{H}_{2}$ (instrumental grade from AGA) and using synthetic air (instrumental grade from AGA) as a fully humidified oxidant. A total back-pressure of 1.5 bar was applied at both the anode and cathode side of the cell. Rotating disk electrode (RDE) measurements were carried out using a three electrode RDE setup from Gamry Instrument in $0.1 \mathrm{M} \mathrm{HClO}_{4}$ solution. $\mathrm{Ag} / \mathrm{AgCl}_{\text {sat }}$ and a graphite rod (6 $\mathrm{mm}$ diameter) served as reference and counter electrode, respectively. The catalyst inks were prepared by manually grinding the catalyst powder followed by mixing $5 \mathrm{mg}$ catalyst, $95 \mu \mathrm{L}$ Nafion solution (5 wt\% in lower aliphatic alcohols and water, Sigma-Aldrich) and $350 \mu \mathrm{L}$ ethanol (99.5\% Solveco). After sonication (30 min) $5 \mu \mathrm{L}$ of the ink was deposit on a polished glassy carbon disk electrode ( $5 \mathrm{~mm}$ diameter, Gamry Instrument) and dried in room temperature for $30 \mathrm{~min}$. The ORR polarization curves were recorded stepwise, every $30 \mathrm{mV}$, with a hold time of $60 \mathrm{~s}$, starting at 1 to $-0.25 \mathrm{~V}$ (vs. RHE) in oxygen saturated electrolyte. The potential was held at the open circuit potential for $120 \mathrm{~s}$ before every polarization experiment. A polarization curve was measured for each catalyst at four different rotation speeds (100, 400, 900 and $1600 \mathrm{rpm}$ ). To achieve the Koutecky-Levich plots the Koutecky-Levich equations presented below were used:

$\frac{1}{i}=\frac{1}{i_{L}}+\frac{1}{i_{K}}=\frac{1}{B w^{1 / 2}}+\frac{1}{i_{K}}$

$B=0.62 n F A C_{0} D_{0}{ }^{2 / 3} v^{-1 / 6}$

Here, $\mathrm{i}_{\mathrm{L}}$ is the diffusion limited current and $\mathrm{i}_{\mathrm{K}}$ the kinetic current. The coefficient used to calculate the number of electron transfer mechanism for each catalyst was obtained from the Faraday constant $(F=96,485 \mathrm{C} / \mathrm{mol})$, the electrode area $\left(A=0.196 \mathrm{~cm}^{2}\right)$, the bulk concentration of $\mathrm{O}_{2}$ in $0.1 \mathrm{M}$ $\mathrm{HClO}_{4}\left(C_{0}=1.2 \times 10^{-3} \mathrm{~mol} / \mathrm{L}\right)$, the diffusion coefficient of $\mathrm{O}_{2}$ in $0.1 \mathrm{M} \mathrm{HClO}_{4}\left(D_{0}=1.93 \times 10^{-5} \mathrm{~cm}^{2} / \mathrm{s}\right)$, and the kinetic viscosity in $\mathrm{HClO}_{4}\left(v=0.00893 \mathrm{~cm}^{2} / \mathrm{s}\right)$.

Physical characterization was made by nitrogen physisorption, X-ray photoelectron spectroscopy (XPS) and electron paramagnetic resonance (EPR) spectroscopy. Nitrogen physisorption measurements were done using a TriStar3000 instrument after degassing the catalyst samples at $225^{\circ} \mathrm{C}$ for $4 \mathrm{~h}$. For XPS measurements a Quantum 2000 scanning ESCA microprobe from physical electronics equipment was used and the samples were mounted on the holders using double-sided conductive tapes. X-band EPR measurements were conducted on the catalysts as powder samples in quartz tubes using a Bruker Elexsys E500 EPR Spectrometer. The modulation power was $6.345 \mathrm{~mW}$ and the modulation amplitude $5 \mathrm{G}$. The samples were measured as-prepared and the sample weight in each quartz EPR-tube was $10 \mathrm{mg}$. The temperature was varied between 295 and $180 \mathrm{~K}$ and the samples were exposed to either air or nitrogen atmospheres.

\section{Results and Discussion}

\subsection{Establishment of a NaOH Etch Method}

The main purpose of this study, is to establish an efficient $\mathrm{NaOH}$ etch method for the synthesis of $\mathrm{Fe}-\mathrm{OMC}$ catalysts. Prior to this study, several trials to remove the silica with a $\mathrm{NaOH}$ etch method were performed on $\mathrm{Fe}-\mathrm{OMCs}$. The trials were performed with $\mathrm{NaOH}$ in aqueous solutions at different concentrations and resulted in either incomplete silica removal or complete removal of silica but with drastically reduced catalytic activity of the catalyst compared to using the HF method (results not included in the paper). The method eventually used, was $\mathrm{NaOH}$ dissolved in a mixture of water and ethanol $[10,11]$. The use of ethanol is advantageous because of its improved wetting of the hydrophobic $\mathrm{Fe}-\mathrm{OMC}$, which enhances the etching through the porous $\mathrm{Fe}-\mathrm{OMC}$ structure. The method was shown to successfully remove the silica, which could be affirmed by the high surface area and pore volume of the catalysts (from the nitrogen-sorption analysis which will be described later), and by absence of silica signal in the XPS-results.

To evaluate if the $\mathrm{NaOH}$ method is suitable for removal of the silica in the synthesis of $\mathrm{Fe}-\mathrm{OMC}$, it was compared to the HF etch method (See experimental methods for details). First, the catalysts were electrochemically evaluated to assess if catalytically active sites were intact after etching. In Fig. 1, polarization curves from single cell fuel cell tests are presented for each catalyst. A large spread in the performance was obtained, where the catalysts etched with the $\mathrm{NaOH}$ etch showed improved fuel cell performance (Fig. 1, turquoise and purple) compared to the HF etched catalysts (Fig. 1, yellow and pink). The differences between the $\mathrm{NaOH}$-etched catalysts and the HF-etched catalysts in the kinetic region are small (see Fig. 1, right), indicating that the two etch methods have a similar influence on the catalytically active sites and that their activities are similar. In the ohmic and mass transport loss regions, the performance is higher for the catalysts treated with the $\mathrm{NaOH}$ etch compared to the HF etched catalysts. This suggests that the $\mathrm{NaOH}$ etch either increases the number of available active sites in the catalyst and/or improves the properties of the carbon matrix, e.g. its conductivity, pore structure, hydrophilicity or mass transport.

To further investigate the observed differences between the catalysts, electrochemical impedance spectroscopy 

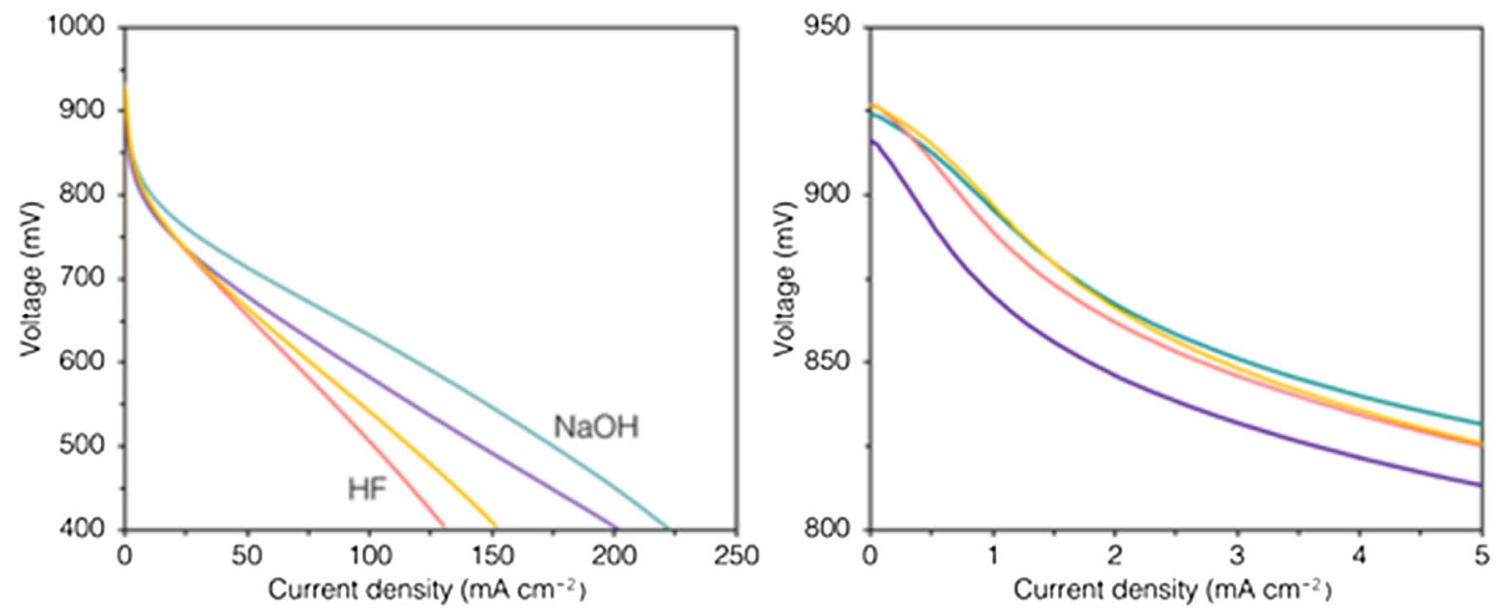

Fig. 1 Polarization curves (left) and zoom-in of the low current density region (right) measured in a single cell PEM fuel cell of AmFe-HF (pink), AmFeAl-HF (yellow), AmFe-NaOH (purple) and AmFeAl-NaOH (turquoise)

measurements were performed on the samples in the fuel cell at $0.7 \mathrm{~V}$ and are presented in Fig. 2 (left). The semicircle in the middle frequency region of the impedance measurements is caused by the dominating cathode activation losses due to the slow reaction kinetics of the oxygen reduction reaction (ORR). The magnitude of the circle depends on the charge transfer resistance and the double layer capacitance of the catalyst [19], but also the number of catalytically active sites and the activity of each site. In Fig. 2, it can be seen that the magnitude of the circle is reduced for the catalysts etched with $\mathrm{NaOH}$, meaning that the charge transfer resistance and the double layer capacitance are reduced in these catalysts.

The catalysts ORR activity was also tested with RDE experiments and the results are presented in Fig. 2 (right). The theoretical number of electrons transferred during the ORR for each catalyst was calculated using the Koutecky-Levich plots obtained from the measurements. All catalysts prepared in this study follow a direct four-electron transfer mechanism indicating ORR active catalysts in accordance with our previous findings of the Fe-OMC catalysts $[17,20]$. The catalysts half-wave potentials were $0.42 \mathrm{~V}$ for AmFe-HF, $0.50 \mathrm{~V}$ for AmFeAl-HF and $0.64 \mathrm{~V}$ $\mathrm{AmFeAl}-\mathrm{NaOH}$ in acidic media $\left(0.1 \mathrm{M} \mathrm{HClO}_{4}\right)$, which is relatively close to the half-wave potentials previously found for $\mathrm{Fe}-\mathrm{OMC}$ catalysts and also other noble metal-free catalysts [21, 22].

To summarize the electrochemical analysis, the $\mathrm{NaOH}$ etch seems to enhance the carbon properties (conductivity and mass transport) of the catalysts. To better understand the etch method's influence on the catalytic performance, we need to look for differences in chemical composition, and surface- and pore
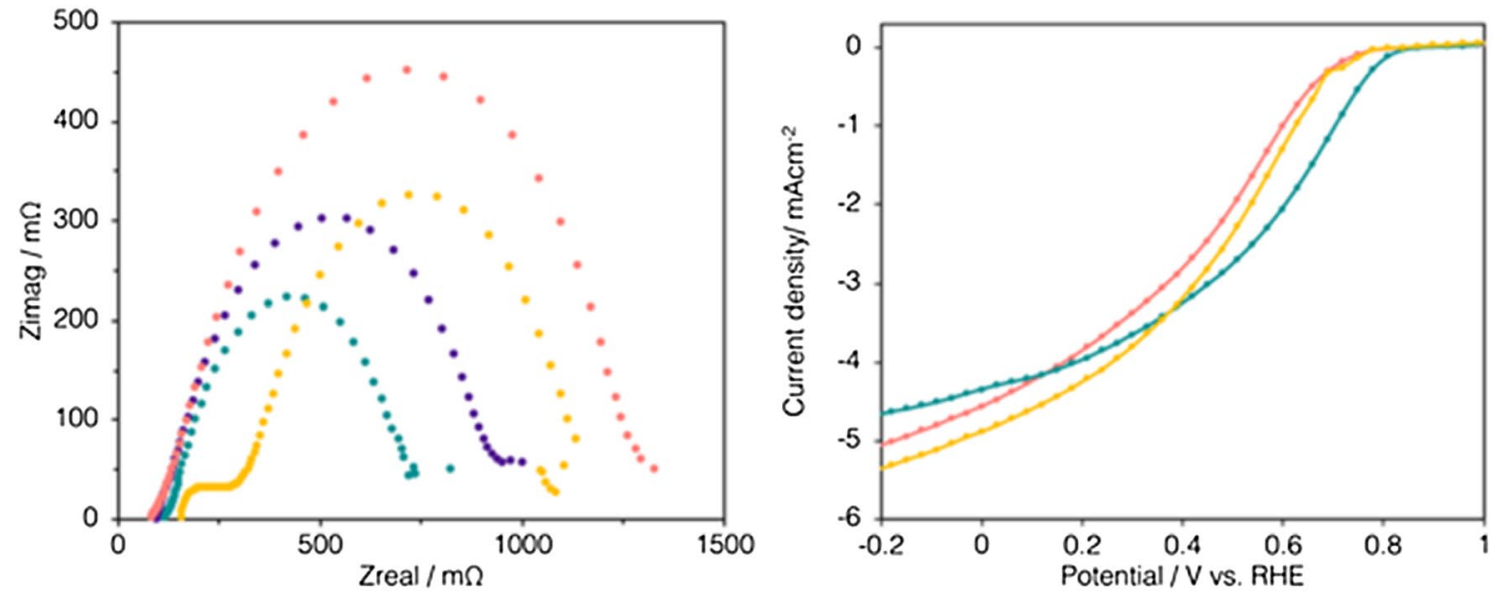

Fig. 2 Nyquist plots at $0.7 \mathrm{~V}$ of (left) measured in a single cell PEM fuel cell and polarization curves (right) measured with RDE of AmFe-HF (pink), AmFeAl-HF (yellow), AmFe- $\mathrm{NaOH}$ (purple) and AmFeAl-NaOH (turquoise) 
properties of the catalysts treated with the $\mathrm{NaOH}$ etch versus the HF etch.

\subsection{Influence of Etch Method on Carbon Properties}

The HF etch of silica is known to proceed with a high etch rate and can be done at room temperature, whereas the $\mathrm{NaOH}$ etch is slower and an elevated temperature (solvent boiling) is needed. The $\mathrm{NaOH}$ etch used here consists of $\mathrm{NaOH}$ dissolved in an ethanol/water mixture. The water is necessary for efficient dissolution of the formed $\mathrm{Na}_{2} \mathrm{SiO}_{3}$, which has a low solubility in ethanol [23]. While ethanol improves the wetting of the hydrophobic carbon pores by the $\mathrm{NaOH}$ solution.

As described in the experimental section, excessive rinsing was made after both etch methods. The catalysts were first rinsed with water, thereafter washed with sulfuric acid and finally pyrolyzed. The sulfuric acid washing step is applied to remove any undesired and soluble iron species that are not bound or coordinated to the carbon-based matrix. Neither sodium or fluorine were expected to be found in the final catalyst after the intense washing. However, from elemental analysis by XPS (data not presented) it was found that small amounts of sodium (0.1-0.4 at.\%) were still left in the catalysts etched with $\mathrm{NaOH}$. This small sodium content could possibly contribute to the increased catalytic activity in the catalysts as will be discussed below.

\subsection{NaOH-Etch for Activation of the Catalysts}

A second purpose of this study was to assess if the $\mathrm{NaOH}$, used for the silica removal, simultaneously can activate the carbon matrix and thereby improve the performance of the catalyst. $\mathrm{NaOH}$ is known to activate carbons at high temperatures through reactions with the carbon described in Reactions (1) and (2) [24, 25] whereby additional porosity and higher specific surface areas are obtained. Depending on the concentration of $\mathrm{NaOH}$, the time of exposure, and the temperature, the carbon will be activated up to a point at which it would eventually decompose completely. An increased sodium hydroxide concentration and longer exposure time would lead to an increased reaction between the sodium and the carbon, pushing the reactions to the right in Reactions (1) and (2), below.

$4 \mathrm{NaOH}+\mathrm{C} \rightarrow 4 \mathrm{Na}+\mathrm{CO}_{2}+2 \mathrm{H}_{2} \mathrm{O}$
$6 \mathrm{NaOH}+2 \mathrm{C} \rightarrow 2 \mathrm{Na}+2 \mathrm{Na}_{2} \mathrm{CO}_{3}(\mathrm{~s}, \mathrm{aq})+3 \mathrm{H}_{2}$

Information about the specific surface area, and pore size and volume were obtained by nitrogen sorption (See Table 2). The difference in nitrogen sorption data from the samples etched with the HF, compared to the $\mathrm{NaOH}$, are small, although some trends can be observed in the results. In the catalysts etched with the $\mathrm{NaOH}$ the total pore volume and the micropore volume are slightly higher compared to the HF etched samples, which could be due to minor carbon activation (from small $\mathrm{NaOH}$ residues in the pyrolysis process), since new micropores are expected to be created when the $\mathrm{NaOH}$ reacts with the carbon in an activation process. Furthermore, the average pore diameters are slightly increased, meaning that the activation process may also enlarge existing mesopores into larger mesopores, without increasing the specific surface area considerably. Additional information about the highly mesoordered structure of the $\mathrm{Fe}-\mathrm{OMCs}$ are visible in the transmission electron microscope images in Fig. 3.

The increased pore diameter could contribute to the increased catalytic performance in the mass transport limited region of the polarization curve since wider pores facilitate the flow through the catalyst particles and increase the mass transport of both oxygen and water in the fuel cell. By creating new micropores, the number of available active sites may increase assuming that some active sites are initially less accessible when incorporated in the carbon matrix.

The fuel cell and the nitrogen sorption results suggested that the two etch methods have a similar influence on the catalytically active sites in the catalyst and that the difference in activity likely is due to differences in properties of the carbon structure. To gain more insight about the active sites and simultaneously about the electronic structure of the supporting carbon matrix the catalysts were probed with EPR spectroscopy. With EPR, unpaired electrons, such as radicals and many transition metal ions can be detected. For the $\mathrm{Fe}-\mathrm{OMC}$ catalysts, EPR can be helpful in investigating different iron species (including most $\mathrm{Fe}(\mathrm{III})$ and high spin $\mathrm{Fe}(\mathrm{II})$ species) and delocalized electrons in the carbon matrix.

In a parallel EPR study on Fe-OMC catalysts [26], we have observed that some EPR signals are highly influenced by the presence of oxygen in the surrounding atmosphere. This is not very surprising since the catalysts are active
Table 2 Specific surface area $\left(\mathrm{S}_{\mathrm{BET}}\right)$, micropore volume

$\left(\mathrm{V}_{\text {micropore }}\right)$, pore volume $\left(\mathrm{V}_{\mathrm{p}}\right)$, and average pore diameter $\left(\varnothing_{\text {ads }}\right)$ of the prepared catalysts calculated from the nitrogen physisorption curves

\begin{tabular}{|c|c|c|c|c|c|c|c|c|c|c|}
\hline \multirow[b]{2}{*}{ Sample } & \multicolumn{2}{|l|}{$\begin{array}{l}\mathrm{S}_{\mathrm{BET}} \\
/ \mathrm{m}^{2} / \mathrm{g}\end{array}$} & \multicolumn{2}{|c|}{$\begin{array}{l}\mathrm{V}_{\text {micropore }} \\
/ \mathrm{cm}^{3} / \mathrm{g}\end{array}$} & \multicolumn{2}{|c|}{$\begin{array}{l}\mathrm{V}_{\mathrm{p}} \\
/ \mathrm{cm}^{3} / \mathrm{g}\end{array}$} & \multicolumn{2}{|c|}{$\begin{array}{l}\mathrm{V}_{\text {micropore }} \\
/ \mathrm{V}_{\mathrm{p}}\end{array}$} & \multicolumn{2}{|l|}{$\begin{array}{l}\emptyset_{\mathrm{ads}} \\
/ \mathrm{nm}\end{array}$} \\
\hline & $\mathrm{HF}$ & $\mathrm{NaOH}$ & $\mathrm{HF}$ & $\mathrm{NaOH}$ & $\mathrm{HF}$ & $\mathrm{NaOH}$ & $\mathrm{HF}$ & $\mathrm{NaOH}$ & $\mathrm{HF}$ & $\mathrm{NaOH}$ \\
\hline $\mathrm{AmFe}-\mathrm{HF} / \mathrm{NaOH}$ & 733 & 666 & 0.037 & 0.043 & 1.00 & 1.01 & 0.037 & 0.042 & 4.77 & 5.37 \\
\hline $\mathrm{AmFeAl}-\mathrm{HF} / \mathrm{NaOH}$ & 1050 & 1070 & 0.060 & 0.070 & 1.19 & 1.33 & 0.051 & 0.052 & 3.98 & 4.23 \\
\hline
\end{tabular}


Fig. 3 TEM images of sample AmFeAl-HF which show the highly ordered mesoporous structure

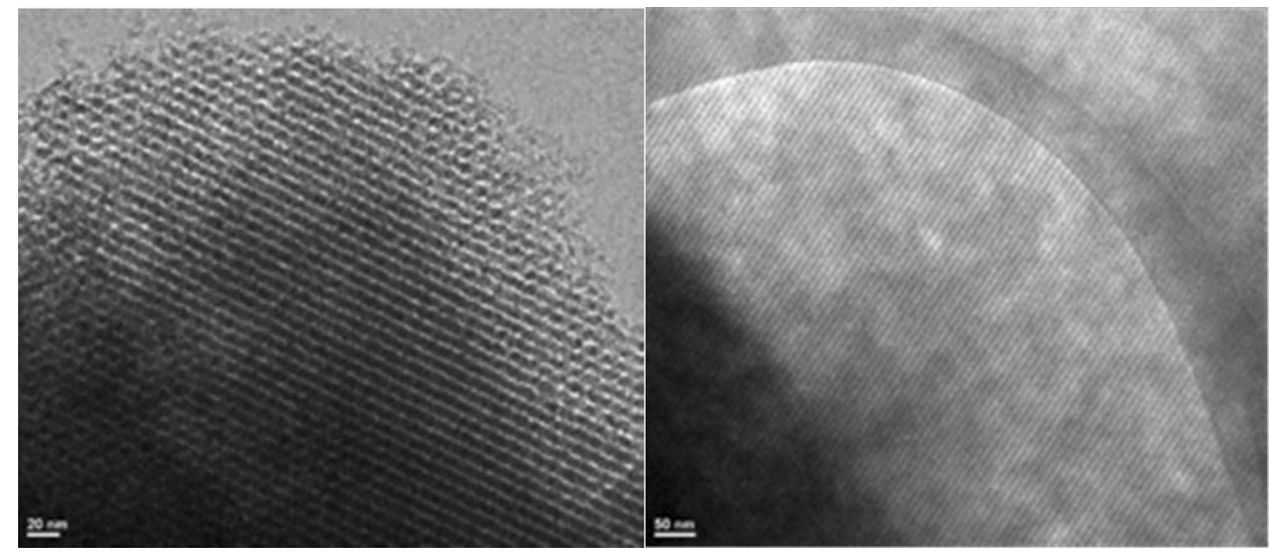

towards the ORR. Consequently, the catalysts studied here were flushed with either air or nitrogen prior to the EPR measurement. The samples were also subjected to two different temperatures $(295 \mathrm{~K}$ and $180 \mathrm{~K}$ ) during the EPR measurements since most EPR-signals have a temperature dependency. In Figs. 4, 5, the EPR spectra are presented for samples AmFeAl-HF and AmFeAl- $\mathrm{NaOH}$ measured at the two different temperatures and in air versus nitrogen atmosphere.

It can be observed that the EPR-signals for the samples etched with $\mathrm{HF}$ or $\mathrm{NaOH}$, respectively, are significantly different. In both samples, we can observe a signal, denoted $\mathrm{R}$, which intensity is increased upon cooling and vanished upon exposure to nitrogen. The signal is associated with an iron(III) species in a rhombic structure with spin state $\mathrm{S}=3 / 2$, which partly is oxidized to a paramagnetic iron(III) species in air and is reduced to an EPR-silent/invisible iron(II) species in nitrogen [26]. It is possible that the species has a role in active sites of the catalysts, but this is not yet fully understood. Another signal, denoted C, is dominating the EPR spectra of the $\mathrm{NaOH}$-sample (and is not at all as dominant in the EPR spectra of the HF-samples). The C signal intensity is decreased upon cooling (Fig. 4) and increased upon exposure to nitrogen (Fig. 5). The $\mathrm{C}$ signal is associated with delocalized electrons in the conductive carbon matrix. The fact that the samples exhibit so different $\mathrm{C}$ signals shows that they have significantly different carbon properties where the sample prepared with the $\mathrm{NaOH}$-etch method likely has a higher conductivity as it exhibits a much higher intensity of the $\mathrm{C}$ signal. Improved conductivity for the samples etched with the $\mathrm{NaOH}$-method could explain the increased catalytic activity at higher current densities obtained in the fuel cell tests.

To summarize, the two silica etch methods investigated in this study, appear to influence the carbon support in $\mathrm{Fe}-\mathrm{OMC}$ catalysts differently. The catalysts etched with the $\mathrm{NaOH}$ method end up with a better catalytic performance (at higher current densities), larger pore sizes, higher micropore
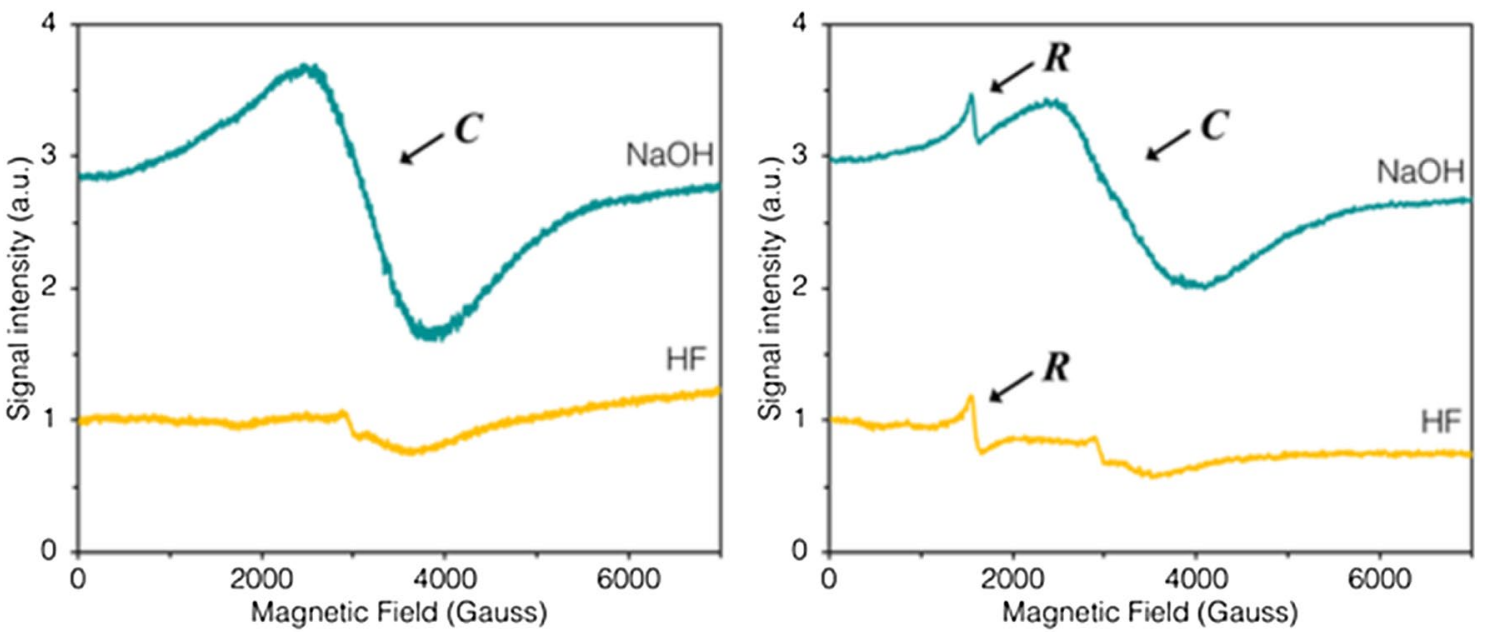

Fig. 4 EPR spectra collected at $295 \mathrm{~K}$ (left) and at $180 \mathrm{~K}$ (right) in air of AmFeAl-NaOH (turquoise) and AmFeAl-HF (yellow), refer to Table 1 for sample preparation details 

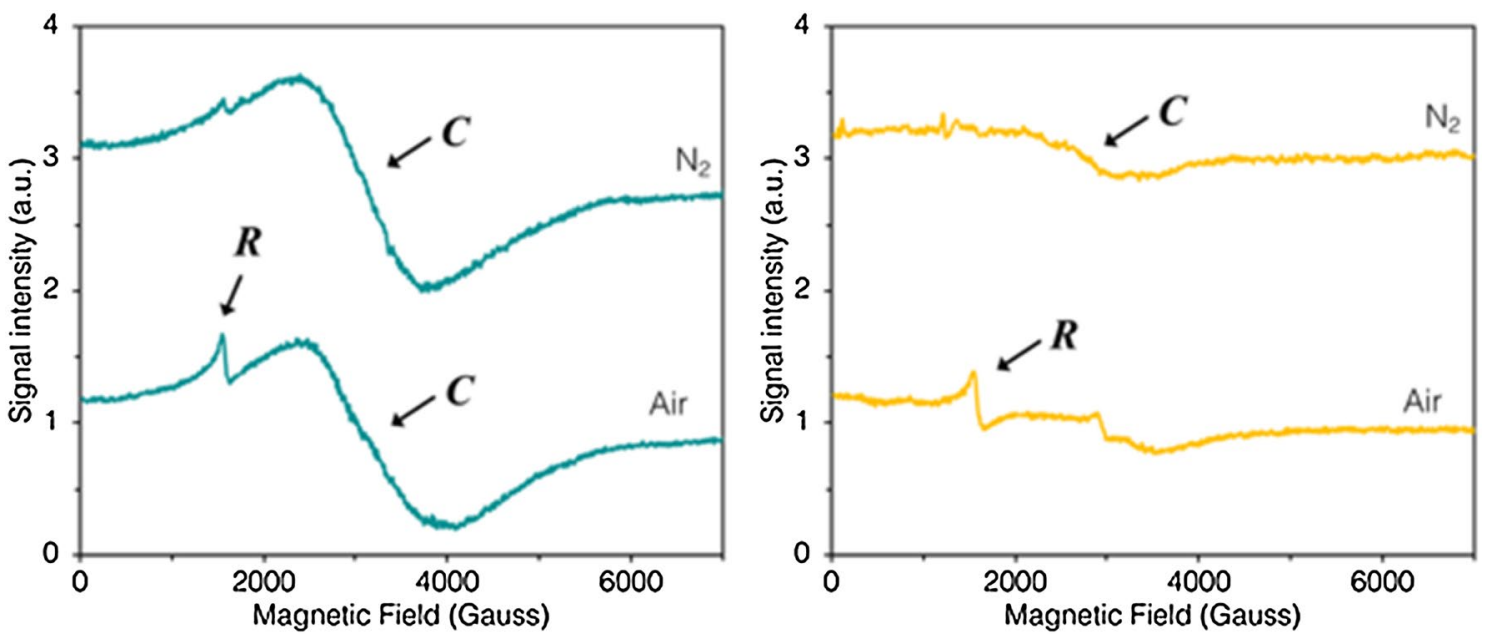

Fig. 5 EPR spectra collected in air (lower traces) and nitrogen (upper traces) at $180 \mathrm{~K}$ of AmFeAl-NaOH (turquoise) and AmFeAl-HF (yellow), refer to Table 1 for sample preparation details

volumes, and possibly also an improved conductivity compared to the catalysts etched with the HF method. One reason for that could be a carbon activation process occurring in the samples etched with the $\mathrm{NaOH}$ method due to $\mathrm{NaOH}$ residuals remaining after the etching step. The $\mathrm{NaOH}$ could then function as an activation agent for the carbon during the second pyrolysis step. The possibility that there may be other reasons that could also contribute to the catalytic performance increase cannot be entirely ruled out at this point.

\section{Conclusion}

In this study, a milder etch method, based on dilute $\mathrm{NaOH}$, was established to replace the currently used HF method in the synthesis of $\mathrm{Fe}-\mathrm{OMC}$ catalysts. The $\mathrm{NaOH}$-etch method was compared to the HF-etch method regarding their influence on the final catalysts in terms of electrochemical, structural and catalytic properties. The $\mathrm{NaOH}$ etch was found to successfully remove the silica template, and interestingly also improve the catalytic performance. The increased catalytic activity was explained by improved properties of the carbon structure for the catalysts treated with the $\mathrm{NaOH}$ etch based on EPR data. The carbon structure was observed to have larger pores and possibly also increased conductivity. With these findings, we show that it is possible to remove the silica in a more user-friendly way and simultaneously increase the catalysts' performance.

Acknowledgements The Swedish Energy Agency, Energimyndigheten, is acknowledged for partly funding this research through project 38340 1. Anne Wendel is gratefully acknowledged for obtaining and treating XPS data.

\section{Compliance with Ethical Standards}

Conflict of interest The authors declare that they have no conflict of interest.

Open Access This article is distributed under the terms of the Creative Commons Attribution 4.0 International License (http://creativeco mmons.org/licenses/by/4.0/), which permits unrestricted use, distribution, and reproduction in any medium, provided you give appropriate credit to the original author(s) and the source, provide a link to the Creative Commons license, and indicate if changes were made.

\section{References}

1. Chen Z, Dodelet J-P, Dodelet JZ (2014) Non-noble metal fuel cell catalysts. Wiley, Weinheim

2. Bashyam R, Zelenay P (2006) A class of non-precious metal composite catalysts for fuel cells. Nature 443(7107):63-66

3. Lefevre M, Proietti E, Jaouen F, Dodelet JP (2009) Iron-based catalysts with improved oxygen reduction activity in polymer electrolyte fuel cells. Science 324(5923):71-74

4. Proietti E, Jaouen F, Lefevre M, Larouche N, Tian J, Herranz J, Dodelet JP (2011) Iron-based cathode catalyst with enhanced power density in polymer electrolyte membrane fuel cells. Nat Commun 2:416

5. Wang YC, Lai YJ, Song L, Zhou ZY, Liu JG, Wang Q, Yang XD, Chen C, Shi W, Zheng YP, Rauf M, Sun SG (2015) S-Doping of an $\mathrm{Fe} / \mathrm{N} / \mathrm{C}$ ORR catalyst for polymer electrolyte membrane fuel cells with high power density. Angew Chem Int Ed 54(34):9907-9910

6. Shui JL, Chen C, Grabstanowicz L, Zhao D, Liu DJ (2015) Highly efficient nonprecious metal catalyst prepared with metal-organic framework in a continuous carbon nanofibrous network. Proc Natl Acad Sci USA 112(34):10629-10634

7. Dombrovskis JK, Jeong HY, Fossum K, Terasaki O, Palmqvist AEC (2013) Transition metal ion-chelating ordered mesoporous carbons as noble metal-free fuel cell catalysts. Chem Mater 25(6):856-861 
8. Dombrovskis JK, Palmqvist AEC (2016) The active site structure of transition metal ion-chelating ordered mesoporous carbon fuel cell catalysts. Fuel Cells 16(1):23-31

9. Dombrovskis JK, Palmqvist AEC (2017) One-pot synthesis of transition metal ion-chelating ordered mesoporous carbon/carbon nanotube composites for active and durable fuel cell catalysts. $\mathrm{J}$ Power Sources 357:87-96

10. Ryoo R, Joo SH, Jun S (1999) Synthesis of highly ordered carbon molecular sieves via template-mediated structural transformation. J Phys Chem B 103(37):7743-7746

11. Jun S, Joo SH, Ryoo R, Kruk M, Jaroniec M, Liu Z, Ohsuna T, Terasaki O (2000) Synthesis of new, nanoporous carbon with hexagonally ordered mesostructure. J Am Chem Soc 122(43):10712-10713

12. Lee J, Han S, Hyeon T (2004) Synthesis of new nanoporous carbon materials using nanostructured silica materials as templates. J Mater Chem 14(4):478-486

13. Kim D, Zussblatt NP, Chung HT, Becwar SM, Zelenay P, Chmelka BF (2018) Highly graphitic mesoporous Fe,N-doped carbon materials for oxygen reduction electrochemical catalysts. ACS Appl Mater Interfaces 10(30):25337-25349

14. Puskás R, Varga T, Grósz A, Sápi A, Oszkó A, Kukovecz Á, Kónya Z (2016) Mesoporous carbon-supported Pd nanoparticles with high specific surface area for cyclohexene hydrogenation: outstanding catalytic activity of $\mathrm{NaOH}$-treated catalysts. Surf Sci 648:114-119

15. Lillo-Ródenas MA, Lozano-Castelló D, Cazorla-Amorós D, Linares-Solano A (2001) Preparation of activated carbons from Spanish anthracite: II. Activation by $\mathrm{NaOH}$. Carbon 39(5):751-759

16. Lillo-Ródenas MA, Cazorla-Amorós D, Linares-Solano A (2003) Understanding chemical reactions between carbons and $\mathrm{NaOH}$ and $\mathrm{KOH}$. Carbon 41(2):267-275

17. Janson C, Palmqvist AEC (2017) Influence of precursor functional groups on the formation and performance of iron-coordinating ordered mesoporous carbons as fuel cell catalysts. J Phys Chem C 121(40):21827-21835
18. Dombrovskis JK, Prestel C, Palmqvist AEC (2014) Optimization of fuel cell membrane electrode assemblies for transition metal ion-chelating ordered mesoporous carbon cathode catalysts. Appl Mater 2:(12)

19. Pletcher D (2009) A first course in electrode processes. The Royal Society of Chemistry, Cambridge

20. Janson C, Dombrovskis JK, Palmqvist AEC, (2018) Influence of iron precursor hydration state on performance of non-precious metal fuel cell catalysts. J Mater Chem A 6(7):3116-3125

21. Shao M, Chang Q, Dodelet JP, Chenitz R (2016) Recent advances in electrocatalysts for oxygen reduction reaction. Chem Rev 116(6):3594-3657

22. Dombrovskis JK, Palmqvist AEC (2016) Recent progress in synthesis, characterization and evaluation of non-precious metal catalysts for the oxygen reduction reaction. Fuel Cells 16(1):4-22

23. Buining PA, Liz-Marzan LM, Philipse AP (1996) A simple preparation of small, smooth silica spheres in a seed alcosol for Stober synthesis. J Colloid Interfaces Sci 179(1):318-321

24. Tseng R-L (2007) Physical and chemical properties and adsorption type of activated carbon prepared from plum kernels by $\mathrm{NaOH}$ activation. J Hazard Mater 147(3):1020-1027

25. Lillo-Ródenas MA, Cazorla-Amorós D, Linares-Solano A (2003) Understanding chemical reactions between carbons and $\mathrm{NaOH}$ and $\mathrm{KOH}$ : an insight into the chemical activation mechanism. Carbon 41(2):267-275

26. Janson C, Palmqvist AEC (2017) Electron Paramagnetic Resonance Spectroscopy Studies of Iron Chelating Ordered Mesoporous Carbons for Oxygen Reduction Catalysis. Manuscript submitted for publication in Communications Chemistry

Publisher's Note Springer Nature remains neutral with regard to jurisdictional claims in published maps and institutional affiliations. 